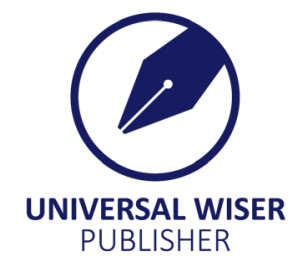

\title{
Integration of Operability Framework and Pareto Optimal Front to Calculate Optimal Condition of Ethane Cracking Process
}

\author{
M. Farsi \\ Department of Chemical Engineering, School of Chemical and Petroleum Engineering, Shiraz University, Shiraz, Iran \\ E-mail: farsi@shirazu.ac.ir
}

\begin{abstract}
The main aim of this research is to present an optimization procedure based on the integration of operability framework and multi-objective optimization concepts to find the single optimal solution of processes. In this regard, the Desired Pareto Index is defined as the ratio of desired Pareto front to the Pareto optimal front as a quantitative criterion to analyze the performance of chemical processes. The Desired Pareto Front is defined as a part of the Pareto front that all outputs are improved compared to the conventional operating condition. To prove the efficiency of proposed optimization method, the operating conditions of ethane cracking process is optimized as a base case. The ethylene and methane production rates are selected as the objectives in the formulated multi-objective optimization problem. Based on the simulation results, applying the obtained operating conditions by the proposed optimization procedure on the ethane cracking process improve ethylene production by about $3 \%$ compared to the conventional condition.
\end{abstract}

Keywords: operability framework, pareto optimal front, process optimization, ethane cracking, mathematical modeling

\section{Nomenclature}

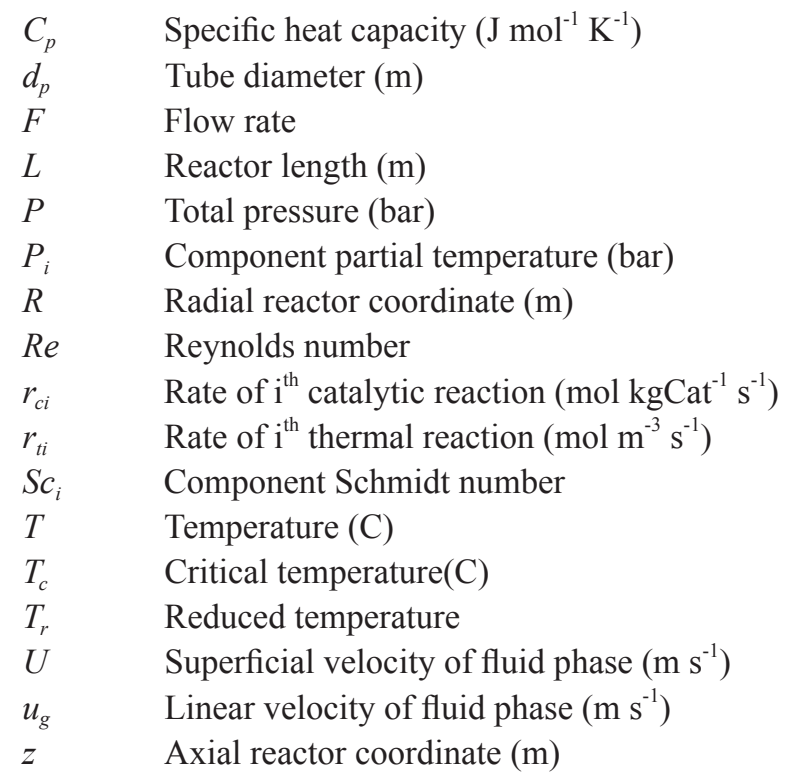

\section{Introduction}

The main objects in the chemical processes is the enhancement of both production capacity and product quality considering the operational, safety, and environmental limitations. However, these goals and limitations may be conflicting and improvement in one objective lead to worsening of the other. Usually, the trade-off between the objectives can be handled by formulation of a multi-objective optimization problem. In the multi-objective optimization problems the objectives are simultaneously satisfied and a set of optimal points are obtained entitle Pareto frontier. All optimal points on the Pareto curve are mathematically equivalent and there is no preferential between solutions ${ }^{[1]}$. 
The considered decisions in the process design stage have a significant effect on the operability, controllability, and plant performance during the process run time. Operability analysis is one of the main bridges between process design and control, which helps the process designer to consider the control issues in the design stage. Indeed, the operability analysis is a measuring criterion to investigate the ability of a process to operate at an acceptable and safe operating point using the available manipulated variable ${ }^{[2,3]}$. Currently, a large number of operability frameworks have been developed to investigate the steady state and dynamic operability of chemical processes. Sharifzadeh presents a good review on the developed methods to investigate the integration of process design and control ${ }^{[4]}$. The proposed methods were presented and the advantages and disadvantages were explained. Farsi et al. investigated the operability characteristics of DME reactor using the framework of Vinson and Georgakis ${ }^{[5]}$. The results showed that the input and output operability index of the process was $43.31 \%$ and $57.58 \%$ respectively.

Ethylene as the simplest olefin compound is a colorless and flammable gaseous hydrocarbon with a sweet odor. It is produced in the petrochemical industry through steam cracking of ethane, propane to naphtha and gas oil. Many researchers have focused on the steam cracking process to produce ethylene and propylene. Yan modeled an ethylene production unit and optimized the operating condition ${ }^{[6]}$. The results showed that separation and refrigeration systems limit the production capacity in the considered plant. Based on the simulation results, applying the optimal condition on the system increased gross profit by $6 \%$ compared to the base case. Caballero et al. optimized the operation condition of an ethane thermal cracker to maximize the ethylene production rate by using the GAMS optimization-modeling platform ${ }^{[7]}$. The cracking reactor was modeled as a one-dimensional tubular reactor considering a detail free-radical kinetic mechanism. The results showed that applying the optimal heat flux on the coil could increase ethane conversion and ethylene selectivity to $81.5 \%$ and $78.9 \%$. Barza et al. modeled the ethane pyrolysis unit in Arya Sasol Petrochemical Company based on the momentum, mass, and energy balance equations ${ }^{[8]}$. Karimi et al. proposed a kinetic model to predict the rates of catalytic and pyrolytic coke formation in the ethane cracking process ${ }^{[9]}$. The simulation results showed that there is a good agreement between the industrial data and the simulations. The proposed dynamic model was used to predict the furnace operating conditions, coke thickness profiles, and the run length of the furnace. Edwin and Balchen focused on the production planning of a thermal cracker considering coke formation ${ }^{[10]}$. They calculated the dynamic trajectories of feed rate and steam concentration during the process run time to achieve maximum profit. The results showed that dynamic optimization gives up to $2 \%$ higher profit compared to steady state optimization. Yancheshmeh et al. modeled ethylene production through thermal cracking of ethane considering steam and carbon dioxide as the dilution ${ }^{[11]}$. The simulation results showed that the thermal cracking process in the presence of $\mathrm{CO}_{2}$ is more effective because of higher ethylene and hydrogen production and less coke thickness.

In this paper, the operability framework and Pareto based multi-objective optimization are integrated and a powerful optimization procedure is developed. To prove the performance of proposed optimization algorithm, the optimal condition of an ethane cracker is determined as a base case. In section 2, the proposed operability based optimization framework, operability index, and the optimal Pareto front are explained. In section 3, the considered kinetic model and developed a mathematical model to simulate the ethane cracking process are presented at steady state condition. In section 4 , the simulation results are presented and compared with the base case at steady state condition.

\section{Optimization framework}

\subsection{Operability index}

In this section, the operability framework introduced by Vinson \& Georgakis is reviewed ${ }^{[12]}$. In this framework, the available process inputs that could change over a certain range are called Available Input Space (AIS). The mathematical model of the process is solved in a range of AIS to obtain the available outputs. The calculated available output points are referred to as the achievable output space (AOS). Besides, the Desired Output Space (DOS) is specified as the desired process outputs by the operator. The set of input variables required to obtain DOS can be calculated from the model inverse. The required input values are denoted as the desired input space (DIS). The Output and Input Operability indexes are defined as:

$$
\mathrm{OOI}=\frac{\mathrm{AOS} \cap \mathrm{DOS}}{\mathrm{AOS}}
$$




$$
\mathrm{IOI}=\frac{\mathrm{AIS} \cap \mathrm{DIS}}{\mathrm{AIS}}
$$

OOI index indicates how much of the desired process outputs are in the range of available outputs. Also, the IOI index indicates how much of the inputs are available to create DOS. The main challenge in the operability analysis is to determine the DOS region in a chemical process. Generally, the DOS is determined by the plant operators.

\subsection{Multi-objective optimization}

In general, problems related to design, modification, and control of chemical processes involve the simultaneous optimization of multiple objectives, which have usually conflict. In these cases, the single-objective optimization could not satisfy all of the desired objectives. Currently, multi-objective optimization has become essential for solving and understanding a wide variety of important problems in the area of chemical engineering ${ }^{[13]}$. Rangaiah et al. presented an acceptable review on the application of multi-objective optimization in chemical processes ${ }^{[14]}$. Multi-objective optimization is a mathematical procedure, which several objective functions are simultaneously optimized. This problem is mathematically formulated as:

$$
\operatorname{Minimize} F(x)=\left[f_{1}(x), f_{2}(x), \ldots, f_{k}(x)\right]
$$

Subject to:

$$
\begin{aligned}
& g_{m}(x) \leq 0 \\
& h_{q}(x)=0
\end{aligned}
$$

Where, $\mathrm{K}, \mathrm{m}$, and q are the number of objectives, inequality, and equality constraints, respectively. The multi-objective approaches allow decision making to think about the trade-offs between different objects. Multi-objective optimization problems satisfy different and even contradictory objectives, which is known as Pareto optimal solutions ${ }^{[15]}$. The vector $\mathrm{F}^{*}$ is a Pareto optimal solution if there does not exist another $F$ in the feasible search region such that $f_{i}(\vec{x}) \leq f_{i}^{*}(\vec{x})$ for all $\mathrm{i} \in\{1,2, \ldots, \mathrm{k}\}$ and $\mathrm{f}_{\mathrm{i}}(\overrightarrow{\mathrm{x}})<\mathrm{f}_{\mathrm{i}}^{*}(\overrightarrow{\mathrm{x}})$ for at least one $\mathrm{i} \in\{1,2, \ldots, \mathrm{k}\}$. Indeed all points on the Pareto set are mathematically equivalent and the decision-maker decides which one of obtained design vectors is appropriate. Finally, the single optimal point is selected from the developed Pareto front by the decision-making method.

\subsection{Developed framework}

In this section, the proposed framework to find the single optimum operating condition of a conventional process is explained considering a multi-objective function. Although the operability framework is effective to determine the range of input variables, it could not determine the optimal operating condition of processes. On the other hand, the main challenge in multi-objective optimization is to determine the range of decision variables. The change in the range of input variables changes the alternatives on the Pareto front, and the different single optimal point is obtained by the decision-making methods. The main object of this research is the integration of operability framework and multi-objective optimization to cover challenges and resolve the weaknesses of those methods.

In multi input-output systems, the output states are developed based on the available inputs considering steady state mathematical model of the process, and the Pareto optimal front is determined based on the calculated outputs. The Desired Pareto front is defined as a part of the Pareto optimal front that all of the outputs present a better performance compared to the conventional condition. This index indicates how much of the developed Pareto optimal front is completely desirable and achievable with the available inputs compared to the current operating condition. Then, the Desired Pareto Index is defined as the ratio of developed desired Pareto front to the Pareto optimal front.

$$
D P I=\frac{\text { Pareto } \cap \text { Desired Pareto }}{\text { Pareto }}
$$

Figure 1 shows the AIS and the calculated AOS based on the AIS in a continuous process with two inputs, $x_{1}$ and $x_{2}$ and two outputs $y_{1}$ and $y_{2}$. The Pareto front, red line, is determined based on the AOS to minimize $y_{1}$ and $y_{2}$, respectively. Since the process operates at a single operating point, one of the points on the Pareto front should be selected as the single 
optimal point. The conventional operating point of the process is determined on the AOS as $y^{\circ}$. Desired Pareto front, blue line, is defined as the operating points that minimize $y_{1}$ and $y_{2}$ simultaneously, and preferred to the conventional operating point. Indeed, the surrounded surface by $y_{1}<y_{1}^{o}, y_{2}<y_{2}^{o}$ and the Pareto front curve is the DOS. In a two-dimensional case, when the length of desired Pareto front approaches to the Pareto front curve, the Desired Pareto Index approaches toward one. It proves that the conventional operating point is far from the optimal condition and process operates at the nonoptimal conditions. In the case that the operating point takes place on the Pareto front, the desired Pareto front is a single point and Desired Pareto Index approaches toward zero. It proves that the process operates at the optimal condition. Indeed the proposed method limits the length of Pareto front based on the conventional operating point and helps the decisionmaker to select a single optimal point based on the conventional operating point. Finally, a single optimal point is selected from the desired optimal front by using decision-making methods. In this research, to prove the performance of proposed method, it is applied to the ethane cracking process to determine the optimal operating condition as a base case.

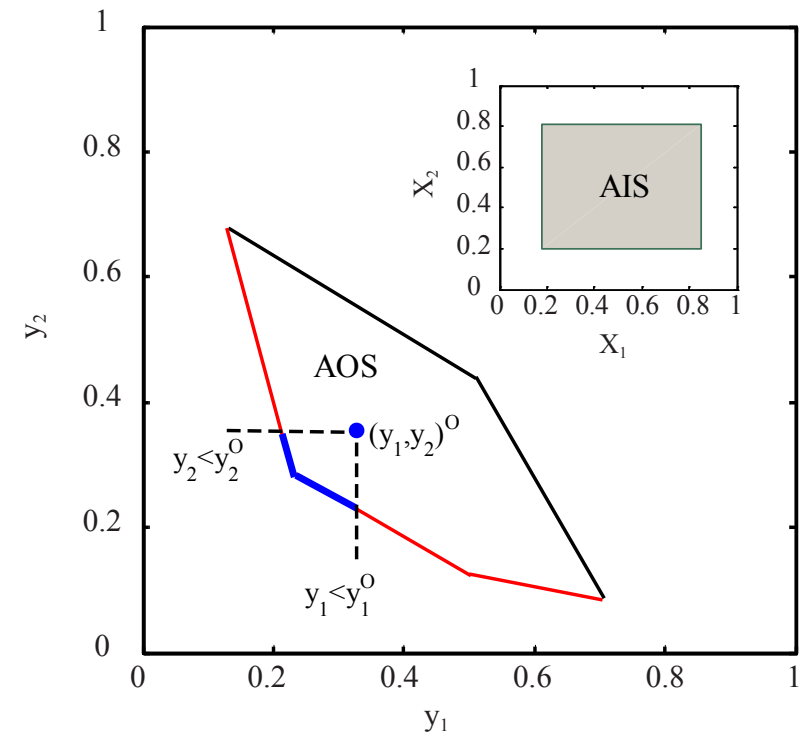

Figure 1. Proposed procedure to select optimum point

\section{Process modeling}

\subsection{Process description}

Typically, the thermal cracking of ethane is carried out in the presence of steam as dilution and in the temperature range $800-900^{\circ} \mathrm{C}^{[16]}$. In the considered thermal cracker, ethane is mixed with high-pressure steam and heated up to 530 $630^{\circ} \mathrm{C}$ in the economizer. Steam as dilution reduces the rate of reactions by decreasing the partial pressure of hydrocarbons. On the other hand, it enhances ethylene selectivity and removes partially coke deposited on the coil tubes. The cracking occurs in the coil hanging at the centerline of the firebox. The dominant heat transfer mechanism in the firebox is thermal radiation supplied by eighty side and bottom burners. In the radiation section, the ethane molecules are cracked into ethylene and hydrogen. The outlet product feeds to the transfer line exchangers and immediately cooled to prevent over cracking. Industrially, when the pressure drop in the coil or skin temperature reaches the critical level, production is stopped and the coil is decoked. Figure 1 shows the schematic diagram of an industrial cracker.

\subsection{Kinetic modeling}

The kinetics of thermal cracking could be explained based on free radical and molecular mechanisms ${ }^{[17]}$. In this research, a molecular kinetic network consisting of 12 species and 11 elementary reactions is selected from literature to predict cracking severity and product distribution. The main reactions in the thermal cracking of ethane are as follows ${ }^{[11]}$ :

$$
\begin{aligned}
& \mathrm{C}_{2} \mathrm{H}_{6} \leftrightarrow \mathrm{C}_{2} \mathrm{H}_{4}+\mathrm{H}_{2} \\
& 2 \mathrm{C}_{2} \mathrm{H}_{6} \rightarrow \mathrm{C}_{3} \mathrm{H}_{8}+\mathrm{CH}_{4} \\
& \mathrm{C}_{3} \mathrm{H}_{6} \leftrightarrow \mathrm{C}_{2} \mathrm{H}_{2}+\mathrm{CH}_{4}
\end{aligned}
$$




$$
\begin{aligned}
& \mathrm{C}_{2} \mathrm{H}_{2}+\mathrm{C}_{2} \mathrm{H}_{4} \leftrightarrow \mathrm{C}_{4} \mathrm{H}_{6} \\
& \mathrm{C}_{2} \mathrm{H}_{6}+\mathrm{C}_{2} \mathrm{H}_{4} \leftrightarrow \mathrm{C}_{3} \mathrm{H}_{6}+\mathrm{CH}_{4} \\
& \mathrm{C}_{3} \mathrm{H}_{8} \rightarrow \mathrm{C}_{3} \mathrm{H}_{6}+\mathrm{H}_{2} \\
& \mathrm{C}_{3} \mathrm{H}_{8} \rightarrow \mathrm{C}_{2} \mathrm{H}_{4}+\mathrm{CH}_{4} \\
& 2 \mathrm{C}_{2} \mathrm{H}_{6} \rightarrow \mathrm{C}_{2} \mathrm{H}_{2}+2 \mathrm{CH}_{4} \\
& \mathrm{C}_{2} \mathrm{H}_{4} \rightarrow \mathrm{Coke} \\
& \mathrm{Coke}+\mathrm{H}_{2} \mathrm{O} \rightarrow \mathrm{CO}+\mathrm{H}_{2} \\
& \mathrm{Coke}+\mathrm{CO}_{2} \rightarrow 2 \mathrm{CO}
\end{aligned}
$$

\subsection{Process model}

In this section, the developed model to simulate the ethane cracker is presented at steady state condition. The considered assumptions to simplification of the model are as follows:

- The gas mixture is in ideal condition due to high temperature and low-pressure.

- Since mass and heat Péclet numbers are considerably large, the radial gradients of temperature and concentration are negligible.

- Quasi-steady state is assumed to simulate the coke deposition rate.

- Since Reynolds number is significantly large, the Plug flow pattern is employed

The mass and energy balances in the coil are as:

$$
\begin{aligned}
& -\frac{1}{\mathrm{~A}_{\mathrm{C}}} \frac{\mathrm{dF}_{i}}{\mathrm{dz}}+\mathrm{r}_{\mathrm{i}}=0 \\
& -\frac{1}{\mathrm{~A}_{\mathrm{C}}} \frac{\mathrm{dF}_{t}}{\mathrm{dz}}+\sum_{\mathrm{j}=1}^{\mathrm{n}} \mathrm{r}_{\mathrm{j}}=0 \\
& -\frac{1}{\mathrm{~A}_{\mathrm{C}}} \mathrm{C}_{\mathrm{p}}^{\mathrm{g}} \frac{\mathrm{d}\left(\mathrm{F}_{\mathrm{t}} \mathrm{T}^{\mathrm{g}}\right)}{\mathrm{dz}}-\sum_{\mathrm{j}=1}^{\mathrm{n}}\left(\Delta \mathrm{H}_{\mathrm{rxn}, \mathrm{j}}\right) \mathrm{r}_{\mathrm{j}}+\mathrm{Q}=0
\end{aligned}
$$

Also, suitable correlations are selected to estimate the physical properties of components and mixture such as viscosity, specific heat capacity, heat conductivity, and diffusion coefficients. Table 1 shows the reactor characteristics and feed specification of a domestic industrial ethane cracker.

Table 1. Characteristics of cracking reactor

\begin{tabular}{cc}
\hline Reactor characteristics & \\
\cline { 2 - 3 } Length $[\mathrm{m}]$ & 78 \\
Inner diameter [m] & 0.1 \\
Wall thickness [mm] & 8 \\
\hline Feed Specification & \\
\hline Ethane flow rate $\left[\mathrm{kg} \mathrm{h}^{-1}\right]$ & 40047 \\
Steam flow rate $\left[\mathrm{kg} \mathrm{h}^{-1}\right]$ & 12014 \\
Inlet temperature $[\mathrm{C}]$ & 695 \\
Inlet pressure $[\mathrm{bar}]$ & 3.05 \\
\hline
\end{tabular}




\section{Results and discussion}

In this section, the simulation results and optimal operating conditions of the process are presented at steady state condition. To analyze the steady state operability of the cracking process, steam flow rate and feed temperature are considered as the input variables. The steam rate changes in rang of 10-20 moles $^{-1}$, while feed temperature varies in rang of 875-905 K. Figure 2 shows the calculated AOS against considered AIS based on the developed mathematical model. It appears that changing the operating condition to maximize ethylene production results in the maximum methane synthesis (point B). In addition, the minimum methane production occurs in point $\mathrm{A}$, where ethylene is at minimum production rate. In the AOS domain, Line $\mathrm{AB}$ and point $\mathrm{O}$ present the Pareto optimal front and conventional operating point in the ethane cracking process, respectively. The operating points on line $\mathrm{CD}$ as a part of the Pareto front improve all objective functions compared to the conventional operating point and defined as the desired Pareto front. The calculated Desired Pareto Index is about 0.12 in the considered cracking process and proves that there is some operating point to improve plant performance considering available input variables. It is mentioned that in a two-dimensional case when the operating point approaches the developed Pareto front, the Desired Pareto Index approaches toward zero and the process operates at the optimal condition. Generally, this approach helps the operator to select a single optimal point from developed desired Pareto front. In this research, the single optimal point is selected from the desired optimal front based on the TOPSIS decision-making method. The TOPSIS is a distance-based decision-making method that recommends the solution with minimum distance from the ideal solution and maximum distance from a non-ideal solution ${ }^{[18]}$. It appears that points $\mathrm{E}$ and $\mathrm{O}$ are ideal and non-ideal solutions, respectively. Since the conventional operating point, $\mathrm{O}$, has been considered as a nonideal solution, the selected optimal solution presents better plant performance. Point $\mathrm{F}$ has been proposed by the TOPSIS method as the single optimal solution of the ethane cracking process. The produced ethylene and methane at the optimal process are 15.62 and 2.34 mole. ${ }^{-1}$, respectively. It appears that the ethylene production rate is improved by about $3 \%$, while methane production decreased by $8.9 \%$ compared to the conventional operating point. Since ethylene production plants have a large capacity and high investment costs, any small enhancement in the process can yield significant financial rewards. It appears that the integration of operability and multi-objective optimization and considering conventional operating point as a reference point limit the length of Pareto front and help the decision-maker to select a single optimal point based on the conventional operating point.

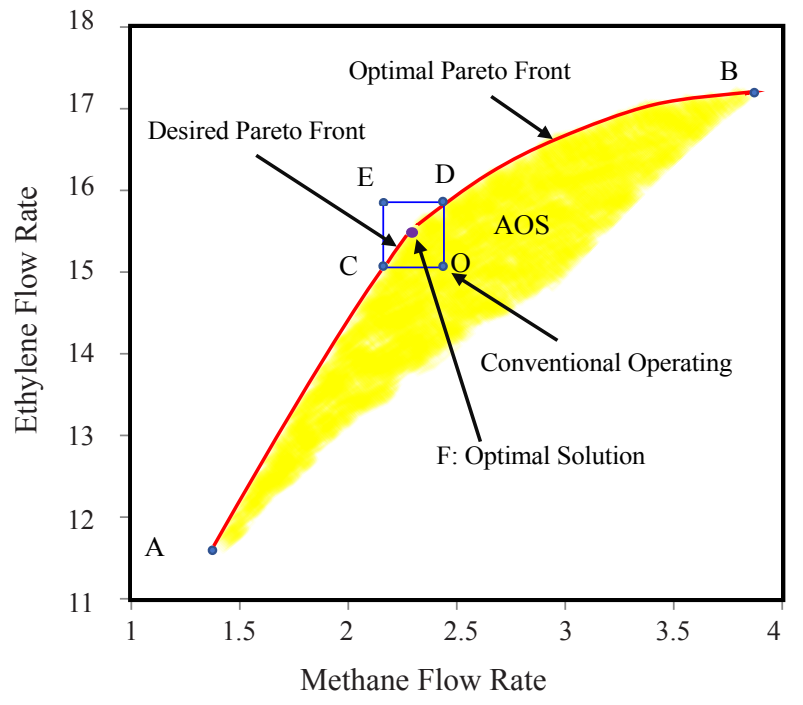

Figure 2. Pareto front and desired pareto front of cracking process

Figure 3 (a-c) shows the ethane conversion, ethylene production yield, and temperature profiles along the reactor. It appears that the difference between ethane conversion in conventional and optimal systems is negligible, while ethylene yield is improved by about $3 \%$. It proves the feasibility and optimality of the selected solution against the conventional condition. 


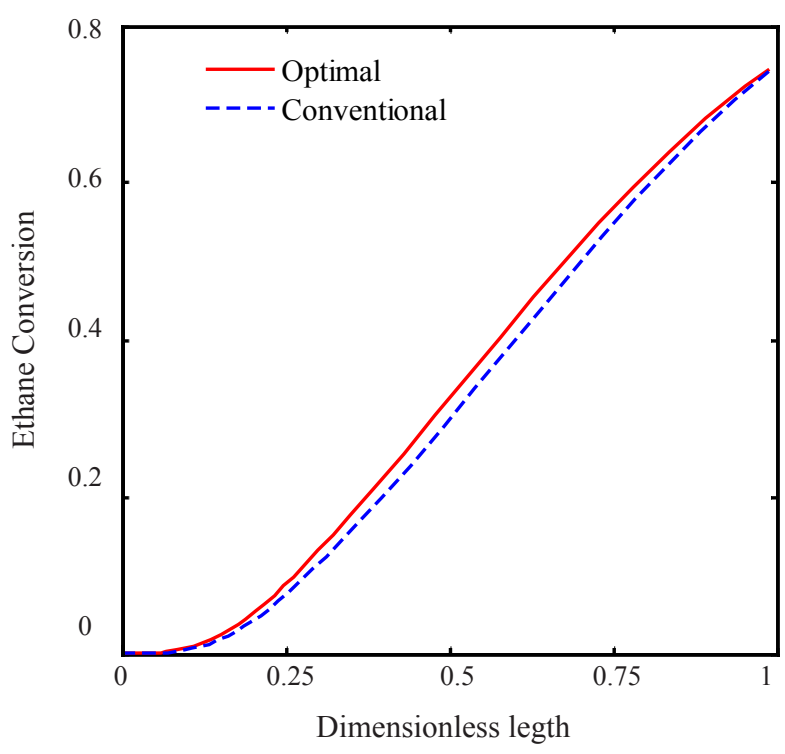

(a)

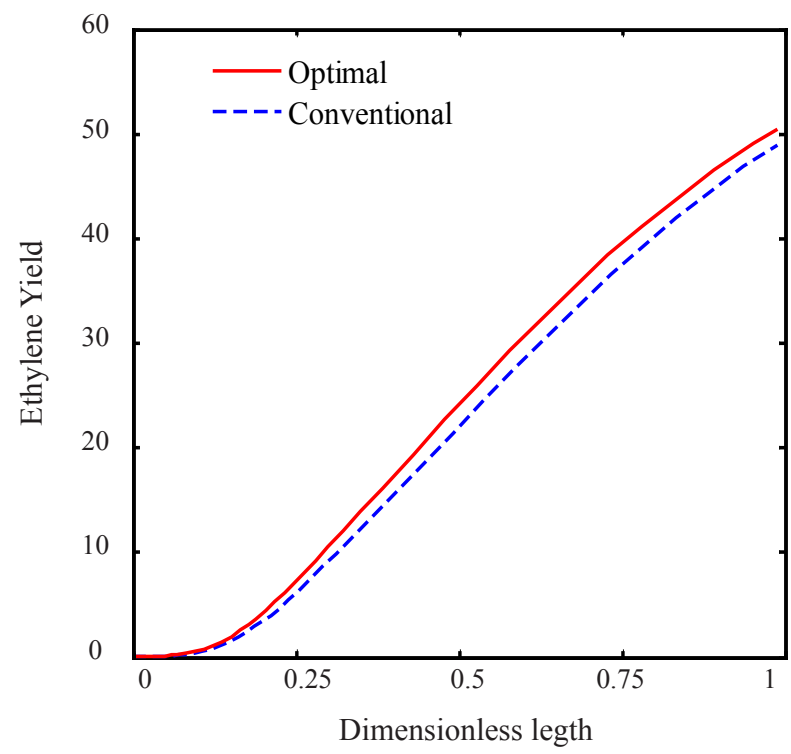

(b)

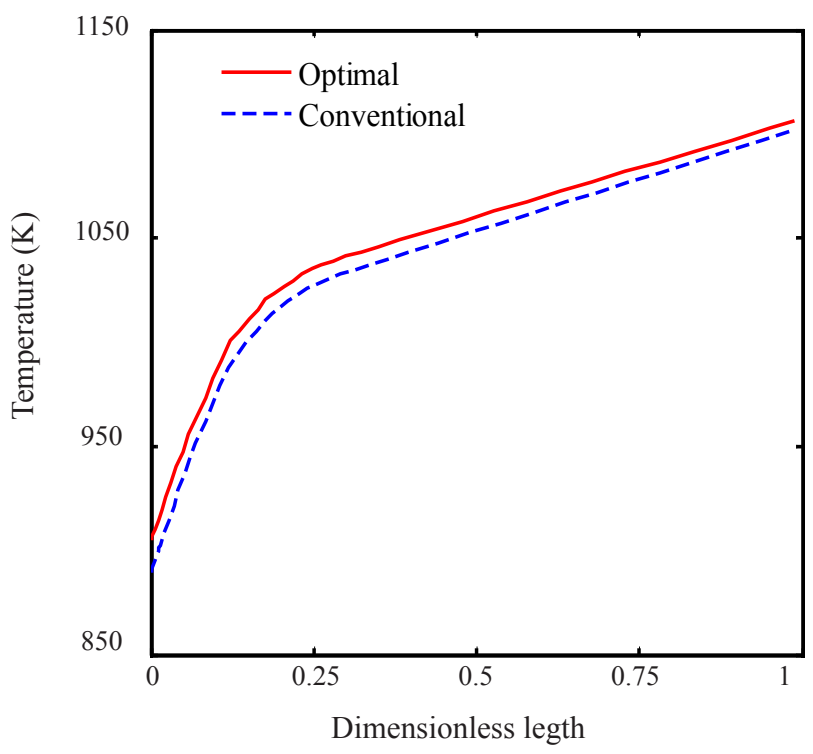

(c)

Figure 3. (a) Ethane conversion, (b) ethylene production yield and (c) temperature profiles along the reactor

Figure 4 (a-b) shows the ethylene and methane production rate along the cracking reactor at steady state condition. It appears that the ethylene mole flow rate increases along the reactor and approaches toward 15.62 mole $\mathrm{s}^{-1}$ in the optimized condition. Generally, there is a considerable difference between the performance of conventional and optimal systems to produce methane and ethylene. Generally, the higher temperature in the optimized system could increase the rate of cracking reactions. On the other hand, the ethane cracking to methane is a second-order reaction, while the ethane to ethylene cracking reaction is first-order based on the ethane concentration. Thus, the higher rate of dilution steam in the optimized condition and decreasing ethane concentration along the reactor have a significant effect on the reactions and results in the lower ethane to methane conversion. 


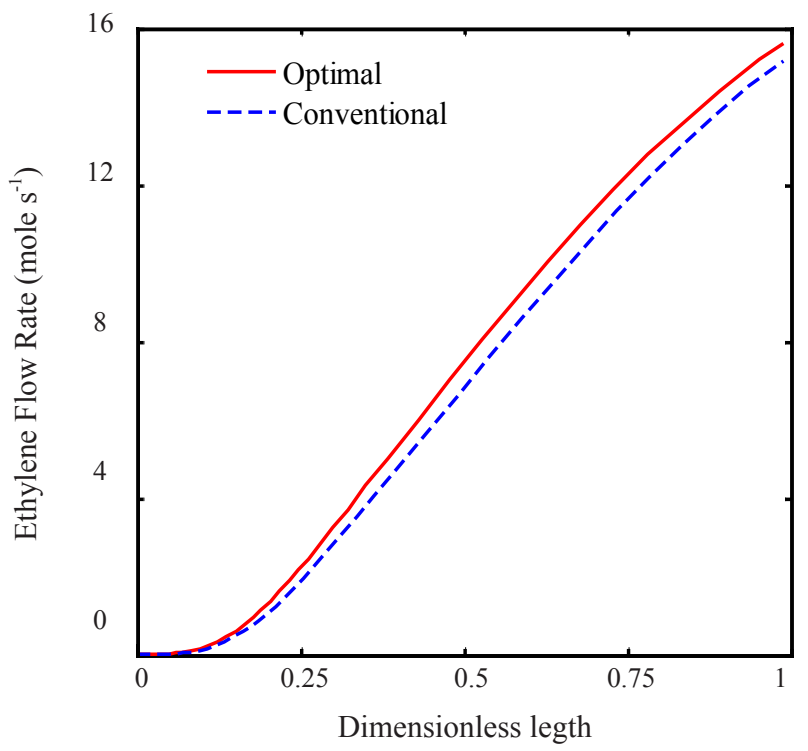

(a)

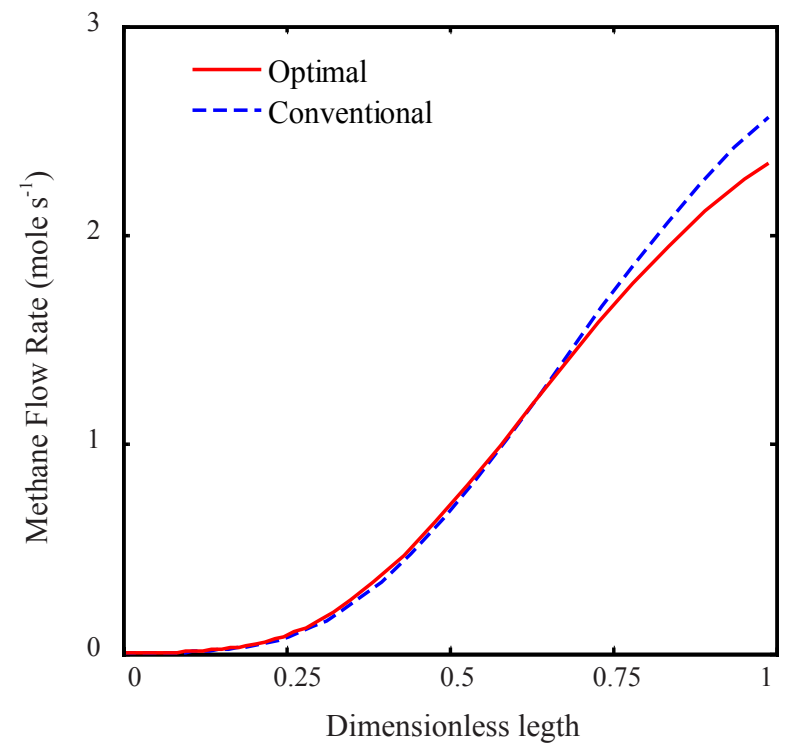

(b)

Figure 4. (a) Ethylene and (b) methane production rate along the cracking reactor

Figure 5 shows the coke thickness profile along the reactor. In the ethane steam cracking plant, a part of produced olefins are converted to coke and deposited on the coil tube as the skin. The formed coke decreases the heat transfer coefficient in the tube and results in higher fuel consumption in the chamber and skin temperature. When the maximum tube surface temperature is obtained, the process is shut down and the decoking cycle is started. In addition, because of coke formation, the effective inner tube diameter decreases and pressure drop increases. Dilution steam decreases hydrocarbon concentration in the reaction zone and results in the lower coke formation. On the other hand, coke is converted to synthesis gas, hydrogen, and carbon monoxide, through steam reforming reactions. Thus, a part of produced coke is removed through the steam reforming. The results show that coke thickness decreases by about $3.8 \%$ in the optimized plant compared to the conventional system.

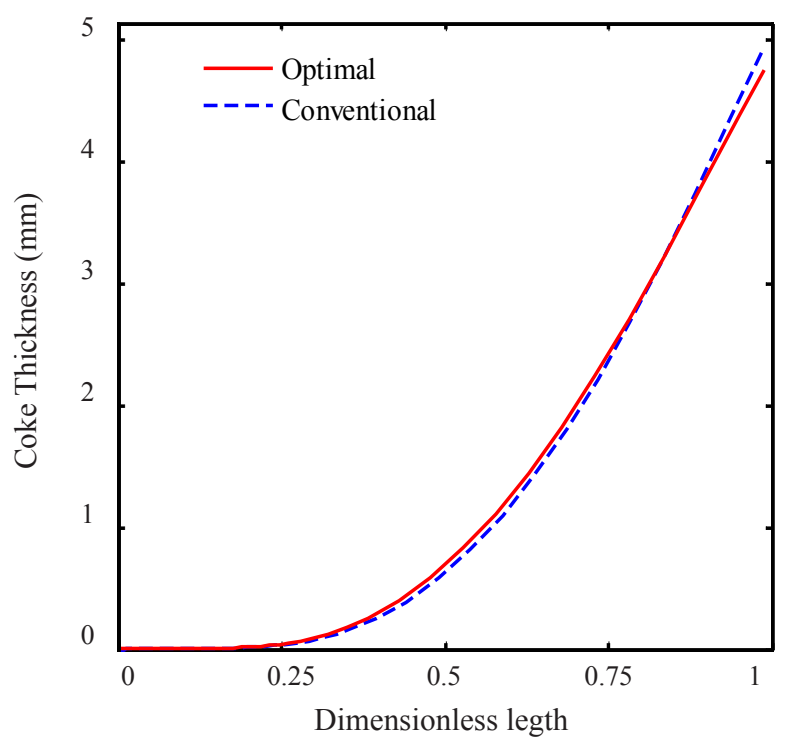

Figure 5. Coke thickness profile along the reactor

\section{Conclusion}

In this research, a quantitative criterion was developed to optimize the performance of chemical processes based on the integration of operability framework and Pareto optimal front. In this regard, the Desired Pareto front was defined as a 
part of the Pareto optimal front that all of the outputs present a better performance compared to the conventional condition. This index indicated how much of the developed Pareto optimal front is completely desirable and achievable with the available inputs compared to the current operating condition. Applying the developed method on the ethane cracker proved that the proposed method limits the length of the Pareto front based on the conventional operating point and helps the decision-maker to select a single optimal point based on the conventional operating point. The simulation results showed that applying the obtained optimal operating points on the ethane cracker improved ethylene production by about $3 \%$ and decreased methane production rate by $8.9 \%$ compared to the conventional operating point.

\section{References}

[1] Deb, K. Multi-objective optimization. In: Edmund K. BurkeGraham Kendall. (eds.) Search methodologies. Boston: Springer; 2014. p.403-449.

[2] Skogestad, S., I. Postlethwaite. Multivariable feedback control: analysis and design. 2nd ed. New York: Wiley; 2007.

[3] Milisavljevic-Syed, J., J.K. Allen, S. Commuri, F. Mistree. Architecting Networked Engineered Systems: Manufacturing Systems Design for Industry 4.0. Springer Nature; 2020.

[4] Sharifzadeh, M. Integration of process design and control: A review. Chemical Engineering Research and Design. 2013; 91(12): 2515-2549.

[5] Farsi, M., S. Mazinani, A. Jahanmiri. Steady state operability characteristics of an adiabatic fixed-bed reactor for methanol dehydration. Iran. J. Chem. Chem. Eng. Research Note Vol. 2011; 30(4).

[6] Yan, M. Simulation and optimization of an ethylene plant. Lubbock: Texas Tech University; 2000.

[7] Caballero, D.Y., L.T. Biegler, R. Guirardello. Simulation and optimization of the ethane cracking process to produce ethylene. In: Krist V. Gernaey, Jakob K. Huusom, Rafiqul Gani. (eds.) Computer Aided Chemical Engineering. Elsevier; 2015; 37: 917-922.

[8] Barza, A., B. Mehri, V. Pirouzfar. Mathematical modeling of ethane cracking furnace of olefin plant with coke formation approach. International Journal of Chemical Reactor Engineering. 2018; 16(9).

[9] Karimi, H., B. Olayiwola, H. Farag, K.B. McAuley. Modelling coke formation in an industrial ethane-cracking furnace for ethylene production. The Canadian Journal of Chemical Engineering. 2020; 98(1): 158-171.

[10] Edwin, E.H., J.G. Balchen. Dynamic optimization and production planning of thermal cracking operation. Chemical engineering science. 2001; 56(3): 989-997.

[11] Yancheshmeh, M.S., S.S. Haghighi, M. Gholipour, O. Dehghani, M. Rahimpour, S. Raeissi. Modeling of ethane pyrolysis process: A study on effects of steam and carbon dioxide on ethylene and hydrogen productions. Chemical Engineering Journal. 2013; 215: 550-560.

[12] Seferlis, P., M.C. Georgiadis. The Integration of Process Design and Control, Volume 17. Elsevier; 2004.

[13] Rangaiah, G.P., A. Petriciolet. Multi-objective optimization in chemical engineering. A John Wiley \& Sons, Ltd., Publication; 2013.

[14] Rangaiah, G.P., Z. Feng, A.F. Hoadley. Multi-objective optimization applications in chemical process engineering: tutorial and review. Processes. 2020; 8(5): 508.

[15] Madetoja, E., H. Ruotsalainen, V.-M. Mönkkönen, J. Hämäläinen, K. Deb. Visualizing multi-dimensional Paretooptimal fronts with a 3D virtual reality system. In: 2008 International Multiconference on Computer Science and Information Technology. Wisia; 2008. p.907-913.

[16] Masoumi, M., S. Sadrameli, J. Towfighi, A. Niaei. Simulation, optimization and control of a thermal cracking furnace. Energy. 2006; 31(4): 516-527.

[17] Moreira, J. Steam Cracking: Kinetics and Feed Characterisation. Master's thesis, Lisboa: Instituto Superior Técnico; 2015.

[18] Etghani, M.M., M.H. Shojaeefard, A. Khalkhali, M. Akbari. A hybrid method of modified NSGA-II and TOPSIS to optimize performance and emissions of a diesel engine using biodiesel. Applied Thermal Engineering. 2013; 59(1): 309-315. 